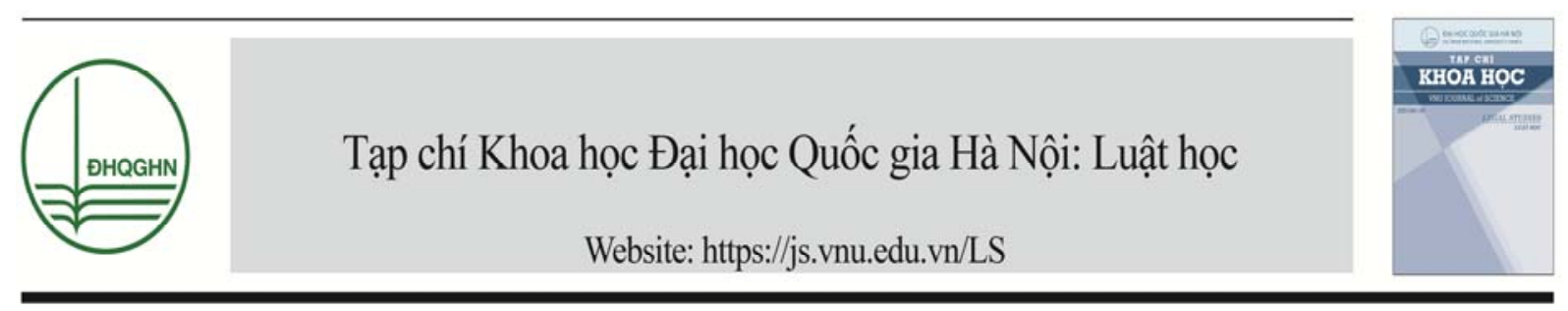

\title{
Hoàn thiện pháp luật về tổ chức đại diện lao động khi Việt Nam gia nhập Hiệp định Đối tác Toàn diện và Tiến bộ xuyên Thái Bình Dương ${ }^{1}$
}

\author{
Lê Thị Hoài Thu* \\ Khoa Luật, Đại học Quốc gia Hà Nội, 144, Xuân Thủy, Cầu Giấy, Hà Nội, Việt Nam \\ Ngày nhận 05 tháng 11 năm 2018 \\ Chỉnh sửa ngày 05 tháng 12 năm 2018; Chấp nhận đăng ngày 24 tháng 12 năm 2018
}

\begin{abstract}
Tóm tắt: Tổ chức đại diện của người lao động là tổ chức bảo vệ quyền và lợi ích hợp pháp của người lao động. Quyền của người lao động trong việc thành lập và gia nhập tổ chức đại diện của người lao động tại cơ sở cần phải được tôn trọng và bảo vệ. Điều này đã được các nước thành viên Hiệp định Đối tác Toàn diện và Tiến bộ xuyên Thái Bình Dương (CPTPP) khẳng định trong cam kết về lao động tại chương 19 của CPTPP. Bài viết chỉ ra thực trạng quy định của pháp luật Việt Nam về tổ chức đại diện lao động để từ đó đưa ra một số kiến nghị hoàn thiện pháp luật về tổ chức đại diện lao động khi Việt Nam gia nhập CPTPP.
\end{abstract}

Tư khóa: Tổ chức đại diện lao động, người lao động, công đoàn, CPTPP.

\section{Khái quát về tổ chức đại diện lao động}

Tổ chức đại diện của người lao động do những người lao động lập nên trên cơ sở của nguyên tắc tự do, tự nguyện, không trái pháp luật với chức năng chủ yếu là đại diện, bảo vệ quyền và lợi ích hợp pháp, chính đáng cho người lao động. Sự thành lập tổ chức đại diện người lao động là một phong trào lớn trên thế

\footnotetext{
*ĐT.: 84-24-37548516.

Email: le hoai thu2002@yahoo.co.uk https://doi.org/10.25073/2588-1167/vnuls.4185

${ }^{1}$ Bài viết này được thực hiện trong khuôn khổ đề tài cấp ĐHQGHN, mã số QG.17.30 "Hoàn thiện pháp luật kinh doanh tại Việt Nam nhằm chuẩn bi cho việc thi hành các hiệp dịnh thuoong mại tụ do (FTA) thế hệ mói" từ năm 2017 đến năm 2019 do PGS.TS. Lê Thị Hoài Thu chủ nhiệm.
}

giới, xuất hiện tại châu Âu vào đầu thế kỉ XIX đồng thời với cuộc cách mạng kĩ nghệ, khi người lao động có nhu cầu cần được bảo vệ trước sức mạnh của người sử dụng lao động và tự ý thức được giá trị của sức mạnh tập thể [1]. So với tổ chức đại diện của người sử dụng lao động, tổ chức đại diện của người lao động ra đời sớm hơn và nhận được sự chú ý nhiều hơn của các giới trong xã hội. Điều này cũng hợp với lẽ tự nhiên, bởi người lao động trong quan hệ làm thuê thường là người yếu thế hơn so với người sử dụng lao động. Về phương diện chính trị, có những nghiệp đoàn độc lập với chính Đảng (nghiệp đoàn của Mỹ, Pháp, Việt Nam cộng hoà), có nghiệp đoàn chi phối chính Đảng (nghiệp đoàn Anh), lại có nghiệp đoàn lệ thuộc 
chính Đảng (nghiệp đoàn ở các quốc gia theo chủ nghĩa xã hội) [2].

Từ khi Tổ chức Lao động quốc tế (ILO) ra đời, việc thành lập, gia nhập, hoạt động trong tổ chức của mình cũng là một nội dung trong quyền tự do liên kết của người lao động được quy định tại Công ước số 87 (năm 1948) và các văn bản có liên quan của ILO. Theo quy định tại Điều 2 Công ước số 87 và các giải thích chính thức của Ủy ban về tự do hiệp hội của ILO, đối tượng áp dụng Công ước là tất cả người lao động, không có bất cứ sự phân biệt dựa trên bất cứ đặc điểm nào như nghề nghiệp, giới tính, tuổi tác, nguồn gốc xuất thân, dân tộc, quốc tịch, tình trạng hôn nhân, quan điểm tôn giáo, chính trị... đều có quyền tự do thành lập hoặc gia nhập công đoàn [3]. Quyền tự do thành lập, gia nhập công đoàn của người lao động theo quy định tại Điều 2 của Công ước số 87 được hiểu rất rộng. Bên cạnh quyền thành lập, gia nhập hay không thành lập, không gia nhập công đoàn, người lao động còn có quyền tự do trong việc quyết định tổ chức của mình có gia nhập, liên kết với tổ chức khác hay không. Điều này đồng nghĩa với việc một tổ chức công đoàn đã được thành lập không thể là rào cản cho việc ra đời một tổ chức công đoàn khác, cả ở cấp doanh nghiệp và các cấp cao hơn.

Trong phạm vi quốc gia, người lao động có thể thành lập một hoặc nhiều tổ chức đại diện của mình tuỳ thuộc vào phạm vi quyền tự do lập hội của người lao động được thừa nhận đến mức độ nào bởi pháp luật quốc gia. Ở các quốc gia không ủng hộ chủ nghĩa đa nguyên thường chỉ tồn tại một loại tổ chức duy nhất đại diện cho người lao động. Ngược lại, ở những quốc gia ủng hộ chủ nghĩa đa nguyên thường có nhiều loại tổ chức khác nhau đại diện cho những nhóm người lao động khác nhau. Trong trường hợp này, các tổ chức đại diện của người lao động phải thảo luận, thương thuyết và đi đến thống nhất cử ra tổ chức có tính đại diện nhất cho giới lao động tham gia cơ chế ba bên (giữa đại diện Nhà nước, đại diện người sử dụng lao động và đại diện người lao động). Khi cần thiết, Nhà nước có thể can thiệp, thậm chí là trực tiếp, vào việc lựa chọn này. Trong phạm vi khu vực và quốc tế, tổ chức đại diện của người lao động có quyền gia nhập tổ chức đại diện của người lao động trong khu vực và gia nhập tổ chức đại diện người lao động ở cấp quốc tế.

Khi tham gia quan hệ lao động (cơ chế phối hợp hai bên và cơ chế ba bên), tổ chức đại diện của người lao động có những vai trò cơ bản như: Là cầu nối người lao động với người sử dụng lao động và Nhà nước; Cùng đại diện của Nhà nước và người sử dụng lao động quyết định hoặc cùng đại diện của người sử dụng lao động tư vấn cho Nhà nước xây dựng chính sách, pháp luật lao động, xây dựng quy hoạch, kế hoạch phát triển kinh tế - xã hội của quốc gia, ngành, vùng...; Phối hợp với hai "đối tác xã hội" còn lại của cơ chế ba bên tổ chức thực hiện chính sách, pháp luật, quy hoạch, kế hoạch... và giải quyết các vấn đề phát sinh từ quá trình tổ chức thực hiện này (bao gồm cả việc giải quyết tranh chấp lao động và đình công); Cùng đại diện người sử dụng lao động xây dựng quan hệ lao động hai bên lành mạnh, môi trường lao động hài hoà, ổn định.

Tuân thủ tiêu chuẩn lao động quốc tế về lao động là nội dung luôn được đề cập đến trong các Hiệp định thương mại tự do thế hệ mới. Cũng như các Hiệp định tự do thương mại thế hệ mới khác, Hiệp định Đối tác Toàn diện và Tiến bộ xuyên Thái Bình Dương (CPTPP) không đưa ra các tiêu chuẩn mới về lao động mà chỉ nhắc lại các tiêu chuẩn lao động đã được quy định trong các Công ước của Tổ chức lao động quốc tế (ILO) mà các nước là thành viên của CPTPP đều có nghĩa vụ tuân thủ, thúc đẩy và thực thi với tư cách là thành viên của ILO, bao gồm: i) Quyền tự do liên kết và thương lượng tập thể; ii) Xóa bỏ lao động cưỡng bức hoặc bắt buộc; iii) Bãi bỏ lao động trẻ em, cấm những hình thức lao động trẻ em tệ hại nhất; iv) Không phân biệt đối xử trong lao động và nghề nghiệp. Theo chương 19 CPTPP, Việt Nam phải tôn trọng và bảo đảm quyền của người lao động trong việc thành lập và gia nhập tổ chức đại diện của người lao động tại cơ sở. Tổ chức đại diện của người lao động tại cơ sở có thể lựa chọn gia nhập Tổng Liên đoàn Lao động Việt Nam hoặc đăng ký với cơ quan nhà nước có 
thẩm quyền để được chính thức hoạt động với tư cách là tổ chức độc lập so với hệ thống Tổng Liên đoàn Lao động Việt Nam (không thuộc về hệ thống Tổng Liên đoàn Lao động Việt Nam). Dù thuộc hay không thuộc hệ thống Tổng Liên đoàn Lao động Việt Nam, tổ chức đại diện của người lao động đều phải tuân thủ Hiến pháp, pháp luật, hoạt động phải phù hợp với tôn chỉ, mục đích và phương thức hoạt động đã được đăng ký. Tôn chỉ, mục đích hoạt động của tổ chức đại diện người lao động phải bảo đảm theo đúng các tiêu chuẩn của ILO là để đại diện, bảo vệ quyền và lợi ích hợp pháp, chính đáng của người lao động thông qua các hình thức tương tác được quy định trong pháp luật bao gồm đối thoại, thương lượng tập thể, đình công và các hành động công nghiệp khác trong quan hệ lao động. Các tổ chức đại diện người lao động không được phép tiến hành bất cứ hoạt động nào có khả năng xâm hại đến an ninh quốc gia, trật tự, an toàn xã hội, không được tham gia bất cứ hoạt động nào ngoài tôn chỉ, mục đích phù hợp với quy định của ILO và đã đăng ký với cơ quan nhà nước có thẩm quyền.

\section{Quy định về tổ chức đại diện lao động trong pháp luật Việt Nam}

Ở Việt Nam, tổ chức Công đoàn - đại diện cho người lao động xuất hiện từ những năm đầu của thế kỉ $X X$ và chính thức được thành lập năm 1929. Con đường ra đời của Công đoàn Việt Nam cũng không nằm ngoài quy luật chung so với con đường ra đời của Nghiệp đoàn công nhân của các quốc gia khác trên thế giới. Cho đến năm 1965, Công đoàn vẫn là tổ chức duy nhất đại diện cho người lao động Việt Nam trong phạm vi cả nước. Từ năm 1965 đến 1975, do hoàn cảnh đất nước bị chia cắt hai miền bởi cuộc kháng chiến chống Mĩ, do người lao động làm thuê trong vùng chiến sự phải làm việc dưới sự điều chỉnh của một hệ thống pháp luật khác (Bộ Luật lao động Việt Nam cộng hòa) và dưới quyền của những người sử dụng lao động không phải là Nhà nước Việt Nam, vì vậy ở miền Nam đã hình thành các tổ chức khác đại diện, đấu tranh bảo vệ quyền lợi cho người lao động, như: Hội lao động giải phóng, Công đoàn giải phóng thuộc Liên hiệp Công đoàn giải phóng miền Nam. Trong suốt thời kì này, giữa Tổng Công đoàn Việt Nam luôn giữ mối quan hệ chặt chẽ với Hội lao động giải phóng và Liên hiệp Công đoàn giải phóng miền Nam. Sau giải phóng miền Nam, ngày 06/6/1976, Hội nghị thống nhất Công đoàn toàn quốc được tổ chức tại thành phố Hồ Chí Minh đã thống nhất các tổ chức đại diện người lao động Việt Nam thành một tổ chức duy nhất là lấy tên là Tổng Công đoàn Việt Nam. Đến năm 1988, Tổng Công đoàn Việt Nam được đổi tên thành Tổng Liên đoàn lao động Việt Nam. Cho đến thời điểm này, tổ chức Công đoàn Việt Nam mới chỉ đại diện cho người lao động trong khu vực Nhà nước. Kể từ khi Nhà nước ta chuyển đổi cơ chế quản lí kinh tế, Công đoàn Việt Nam ngày càng mở rộng phạm vi hoạt động và dần trở thành tổ chức đại diện cho toàn thể người lao động Việt Nam trong cả khu vực Nhà nước và ngoài khu vực Nhà nước [4].

Khi chuyển sang nền kinh tế thị trường, vấn đề đại diện lao động ở nước ta được ghi nhận trong Quy chế lao động đối với các xí nghiệp có vốn đầu tư nước ngoài ban hành kèm theo Nghị định số 233/HĐBT ngày 22/06/1990 của Hội đồng bộ trưởng (nay là Chính phủ) quy định: "Đại diện lao động là chủ tịch hoặc người được ủy quyền của Ban chấp hành công đoàn thuộc hệ thống Tổng Liên đoàn Lao động Việt Nam; hoặc là người được đại diện tập thể lao động trong xí nghiệp cử ra thay mặt cho họ, khi trong xí nghiệp chưa có tổ chức công đoàn" (khoản 2 , Điều 2). Ngoài ra, đại diện lao động còn được quy định trong Bản quy định về thỏa ước lao động tập thể, ban hành kèm theo Nghị định số 18/CP ngày 26/12/1992 của Chính phủ. Theo Bản quy định này thì: "Ban đại diện lao động có ít nhất là ba người, do tập thể lao động trong doanh nghiệp bầu ra và được cơ quan lao động cấp tỉnh xác nhận". Việc bầu ban đại diện lao động được tiến hành trong các doanh nghiệp "chưa có tổ chức công đoàn" (điểm b khoản 1 Điều 6). Trong trường hợp doanh nghiệp đã có tổ chức công đoàn nhưng số lượng đoàn viên công đoàn dưới $50 \%$ số lượng người lao động 
thì "Ban Chấp hành Công đoàn nơi đó phải tổ chức bầu thêm đại diện của những người lao động chưa là đoàn viên công đoàn" (điểm a khoản 1 Điều 6). Mặc dù các văn bản nói trên đều không còn hiệu lực nhưng cũng cho thấy pháp luật đã thừa nhận và quy định đại diện lao động bao gồm: tổ chức công đoàn cơ sở hoặc đại diện do tập thể lao động bầu nên. Tính chất đa công đoàn ở khía cạnh nào đó đã được thừa nhận và thực hiện trong vấn đề đại diện lao động [5].

Hiện nay, đại diện lao động ở Việt Nam được quy định tại Luật công đoàn năm 2012; Bộ luật lao động năm 2012, Nghị định số 43/2013/NĐ-CP ngày 10/5/2013 của Chính phủ quy định chi tiết thi hành Điều 10 của Luật công đoàn về quyền, trách nhiệm của công đoàn trong việc đại diện, bảo vệ quyền, lợi ích hợp pháp, chính đáng của người lao động, Nghị định số 191/2013/NĐ-CP ngày 21/11/2013 của Chính phủ quy định chi tiết về tài chính công đoàn, Nghị định số 200/2013/NĐ-CP ngày 26/11/2013 của Chính phủ quy định chi tiết thi hành Điều 11 Luật công đoàn về quyền, trách nhiệm của công đoàn trong việc tham gia quản lí nhà nước, quản lí kinh tế - xã hội, Điều lệ Công đoàn Việt Nam năm 2013 và một số văn bản pháp luật khác.

Theo quy định của các văn bản pháp luật nêu trên, đại diện lao động ở Việt Nam là tổ chức công đoàn được quy định tại Điều 1 Luật công đoàn năm 2012: "Công đoàn là tổ chức chính trị - xã họi rộng lớn của giai cấp công nhân và của nguời lao động, được thành lập trên co sở tư nguyện, là thành viên trong hệ thống chinh trị của xã hội Việt Nam, duơoi sư lãnh đạo của Đảng Cộng sản Việt Nam; đại diện cho cán bộ, công chức, viên chức, công nhân và nhũng người lao động khác (sau đây gọi chung là người lao động), cùng với co quan nhà nước, tổ chức kinh tế, tồ chức xã hội chăm lo và bảo vệ quyền, lợi ich hợp pháp, chính đáng của nguời lao động; tham gia quản lí nhà nước, quản li kinh tế - xã họi, tham gia thanh tra, kiêm tra, giám sát hoạt động của co quan nhà nước, tổ chức, đơn vị, doanh nghiẹp; tuyên truyền, vận động nguời lao động học tập nâng cao trình độ, kỹ năng nghề nghiệp, chấp hành pháp luật, xây dụng và bảo vệ Tổ quốc Việt Nam xã hôi chủ nghĩa". Nội dung quy định về đại diện lao động bao gồm:

Thú nhất, quyền thành lập, gia nhập và hoạt động công đoàn của người lao động.

Theo quy định tại Điều 5 Luật Công đoàn và Điều lệ Công đoàn Việt Nam, người lao động là ngườiViệt Nam làm việc trong cơ quan, tổ chức, doanh nghiệp có quyền thành lập, gia nhập và hoạt động công đoàn theo quy định của Điều lệ Công đoàn Việt Nam.

Thư hai, chức năng, quyền, trách nhiệm của Công đoàn.

Các chức năng cơ bản của Công đoàn Việt Nam bao gồm: i) Đại diện và bảo vệ quyền, lợi ích hợp pháp, chính đáng của người lao động; ii) Tham gia quản lí nhà nước, quản lí kinh tế xã hội; iii) Vận động, giáo dục người lao động.

Để thực hiện các chức năng trên, Nhà nước quy định cho Công đoàn Việt Nam những nhiệm vụ trong Luật Công đoàn năm 2012, bao gồm: i) Đại diện, bảo vệ quyền, lợi ích hợp pháp, chính đáng của người lao động (Điều 10 Luật Công đoàn, Nghị định số 43/2013/NĐ$\mathrm{CP})$; ii) Tham gia quản lí nhà nước, quản lí kinh tế - xã hội (Điều 11 Luật công đoàn, Nghị định số 200/2013/NĐ-CP; iii) Trình dự án luật, pháp lệnh và kiến nghị xây dựng chính sách, pháp luật (Điều 12 Luật công đoàn); iv) Tham dự các phiên họp, cuộc họp, kì họp và hội nghị (Điều 13 Luật công đoàn); v) Tham gia thanh tra, kiểm tra, giám sát hoạt động của cơ quan, tổ chức, doanh nghiệp (Điều 14 Luật công đoàn); vi) Tuyên truyền, vận động, giáo dục người lao động (Điều 15 Luật công đoàn); vi) Phát triển đoàn viên công đoàn và công đoàn cơ sở (Điều 16 Luật công đoàn).

Trên cơ sở các nhiệm vụ được quy định tại Luật công đoàn, tại mỗi kì Đại hội toàn quốc, Tổng Liên đoàn lao động Việt Nam đã cụ thể hoá thành những nhiệm vụ cụ thể cho từng giai đoạn. Mỗi cấp tổ chức của Công đoàn có những quyền hạn cụ thể để thực hiện chức năng, nhiệm vụ của công đoàn phù hợp với từng cấp trong hệ thống tổ chức của Công đoàn. 
Thú $b a$, quyền, trách nhiệm của đoàn viên công đoàn.

Quyền của đoàn viên công đoàn được quy định tại Điều 18 Luật công đoàn, bao gồm: i) Yêu cầu Công đoàn đại diện, bảo vệ quyền, lợi ích hợp pháp, chính đáng khi bị xâm phạm; ii) Được thông tin, thảo luận, đề xuất và biểu quyết công việc của Công đoàn; được thông tin về đường lối, chủ trương, chính sách của Đảng và pháp luật của Nhà nước liên quan đến Công đoàn, người lao động; quy định của Công đoàn; iii) Ứng cử, đề cử, bầu cử cơ quan lãnh đạo công đoàn theo quy định của Điều lệ Công đoàn Việt Nam; chất vấn cán bộ lãnh đạo công đoàn; kiến nghị xử lí kỉ luật cán bộ công đoàn có sai phạm; iv) Được Công đoàn tư vấn pháp luật, trợ giúp pháp lí miễn phí pháp luật về lao động, công đoàn; v) Được Công đoàn hướng dẫn giúp đỡ tìm việc làm, học nghề; thăm hỏi, giúp đỡ lúc ốm đau hoặc khi gặp hoàn cảnh khó khăn; vi) Tham gia hoạt động văn hoá, thể thao, du lịch do Công đoàn tổ chức; vii) Đề xuất với Công đoàn kiến nghị cơ quan, tổ chức, doanh nghiệp về việc thực hiện chế độ, chính sách, pháp luật đối với người lao động.

Trách nhiệm của đoàn viên công đoàn được quy định tại Điều 19 Luật công đoàn, bao gồm: i) Chấp hành và thực hiện Điều lệ Công đoàn Việt Nam, nghị quyết của Công đoàn; tham gia các hoạt động công đoàn, xây dựng tổ chức công đoàn vững mạnh; ii) Học tập nâng cao trình độ chính trị, văn hoá, chuyên môn, kỹ năng nghề nghiệp; rèn luyện phẩm chất giai cấp công nhân; sống và làm việc theo Hiến pháp và pháp luật; iii) Đoàn kết, giúp đỡ đồng nghiệp nâng cao trình độ, kỹ năng nghề nghiệp, lao động có hiệu quả và bảo vệ quyền, lợi ích hợp pháp, chính đáng của người lao động và tổ chức công đoàn.

Thư $t u$, trách nhiệm của Nhà nước, cơ quan nhà nước, tổ chức, doanh nghiệp đối với Công đoàn.

Trách nhiệm của Nhà nước, cơ quan nhà nước, tổ chức, doanh nghiệp đối với Công đoàn được quy định tại Chương III Luật công đoàn, bao gồm: i) Quan hệ giữa Công đoàn với Nhà nước, cơ quan, tổ chức, doanh nghiệp (Điều 20): là quan hệ hợp tác, phối hợp để thực hiện chức năng, quyền, trách nhiệm của các bên theo quy định của pháp luật, góp phần xây dựng quan hệ lao động hài hoà, ồn định và tiến bộ.

ii) Trách nhiệm của Nhà nước đối với Công đoàn (Điều 21): Bảo đảm, hỗ trợ, tạo điều kiện cho Công đoàn thực hiện chức năng, quyền, trách nhiệm theo quy định của pháp luật; Tuyên truyền, phổ biến, giáo dục pháp luật về lao động, công đoàn và quy định khác của pháp luật có liên quan đến tồ chức công đoàn, quyền, nghĩa vụ của người lao động; Thanh tra, kiểm tra, giám sát và xử lí hành vi vi phạm pháp luật về công đoàn; Phối hợp với Công đoàn chăm lo và bảo đảm quyền, lợi ích hợp pháp, chính đáng của người lao động; Lấy ý kiến của Công đoàn khi xây dựng chính sách, pháp luật liên quan trực tiếp đến tổ chức công đoàn, quyền, nghĩa vụ của người lao động; Phối hợp và tạo điều kiện để Công đoàn tham gia quản lí nhà nước, quản lí kinh tế - xã hội, đại diện, bảo vệ quyền, lợi ích hợp pháp, chính đáng của người lao động.

iii) Trách nhiệm của cơ quan, tổ chức, doanh nghiệp đối với Công đoàn (Điều 22): Phối hợp với Công đoàn thực hiện chức năng, quyền, nghĩa vụ của các bên theo quy định của pháp luật; Tạo điều kiện cho người lao động thành lập, gia nhập và hoạt động công đoàn; Phối hợp với công đoàn cùng cấp xây dựng, ban hành và thực hiện quy chế phối hợp hoạt động; Thừa nhận và tạo điều kiện để công đoàn cơ sở thực hiện quyền, trách nhiệm theo quy định của pháp luật; Trao đổi, cung cấp đầy đủ, chính xác, kịp thời thông tin liên quan đến tổ chức, hoạt động của cơ quan, tổ chức, doanh nghiệp theo quy định của pháp luật khi Công đoàn đề nghị; Phối hợp với Công đoàn tổ chức đối thoại, thương lượng, ký kết, thực hiện thoả ước lao động tập thể và quy chế dân chủ cơ sở; Lấy ý kiến của công đoàn cùng cấp trước khi quyết định những vấn đề liên quan đến quyền, nghĩa vụ của người lao động; Phối hợp với Công đoàn giải quyết tranh chấp lao động và những vấn đề liên quan đến việc thực hiện pháp luật về lao động; Bảo đảm điều kiện hoạt động công đoàn, 
cán bộ công đoàn và đóng kinh phí công đoàn theo quy định.

Thứ năm, bảo đảm hoạt động của Công đoàn.

Những bảo đảm hoạt động của Công đoàn được quy định tại Chương IV của Luật công đoàn, bao gồm:

i) Bảo đảm về tổ chức, cán bộ (Điều 23): Công đoàn các cấp được bảo đảm về tổ chức và số lượng cán bộ, công chức để thực hiện chức năng, quyền, trách nhiệm theo quy định của pháp luật. Căn cứ vào yêu cầu nhiệm vụ của từng công đoàn cơ sở và số lượng lao động trong cơ quan, tổ chức, doanh nghiệp, cơ quan có thẩm quyền quản lí cán bộ công đoàn quyết định bố trí cán bộ công đoàn chuyên trách.

ii) Bảo đảm điều kiện hoạt động công đoàn (Điều 24): Cơ quan, tổ chức, doanh nghiệp có trách nhiệm bố trí nơi làm việc và tạo điều kiện về phương tiện làm việc cần thiết cho công đoàn cùng cấp hoạt động. Cán bộ công đoàn không chuyên trách được sử dụng 24 giờ làm việc trong một tháng đối với Chủ tịch, Phó Chủ tịch công đoàn cơ sở, 12 giờ làm việc trong 01 tháng đối với Ủy viên Ban chấp hành, Tổ trưởng, Tổ phó tổ công đoàn để làm công tác công đoàn và được đơn vị sử dụng lao động trả lương. Cán bộ công đoàn không chuyên trách được nghỉ làm việc và được hưởng lương do đơn vị sử dụng lao động chi trả trong những ngày tham dự cuộc họp, tập huấn do công đoàn cấp trên triệu tập. Cán bộ công đoàn không chuyên trách do đơn vị sử dụng lao động trả lương, được hưởng phụ cấp trách nhiệm cán bộ công đoàn theo quy định của Tổng Liên đoàn Lao động Việt Nam. Cán bộ công đoàn chuyên trách do Công đoàn trả lương, được đơn vị sử dụng lao động bảo đảm quyền lợi và phúc lợi tập thể như người lao động đang làm việc trong cơ quan, tổ chức, doanh nghiệp.

iii) Bảo đảm cho cán bộ công đoàn (Điều 25): Cán bộ công đoàn không chuyên trách đang trong nhiệm kì khi hợp đồng lao động hết hạn được gia hạn hợp đồng lao động, hợp đồng làm việc đến hết nhiệm kì. Người sử dụng lao động không được đơn phương chấm dứt hợp đồng lao động, hợp đồng làm việc, sa thải, buộc thôi việc hoặc thuyên chuyển công tác đối với cán bộ công đoàn không chuyên trách nếu không có ý kiến thỏa thuận bằng văn bản của Ban chấp hành công đoàn cơ sở hoặc Ban chấp hành công đoàn cấp trên trực tiếp cơ sở. Trường hợp người lao động là cán bộ công đoàn không chuyên trách bị cơ quan, tổ chức, doanh nghiệp chấm dứt hợp đồng lao động, hợp đồng làm việc, buộc thôi việc hoặc sa thải trái pháp luật thì Công đoàn có trách nhiệm yêu cầu cơ quan nhà nước có thẩm quyền can thiệp; nếu được ủy quyền thì Công đoàn đại diện khởi kiện tại Toà án để bảo vệ quyền, lợi ích hợp pháp cho cán bộ công đoàn; đồng thời hỗ trợ tìm việc làm mới và trợ cấp trong thời gian gián đoạn việc làm theo quy định của Tổng Liên đoàn Lao động Việt Nam.

iv) Ngoài ra, Luật công đoàn còn quy định về tài chính công đoàn (Điều 26), quản lí, sử dụng tài chính công đoàn (Điều 27), kiểm tra, giám sát tài chính công đoàn (Điều 29), Tài sản công đoàn (Điều 28 ) và kiểm tra, giám sát tài chính công đoàn (Điều 29).

Thư sáu, giải quyết tranh chấp và xử lí vi phạm pháp luật về công đoàn.

Theo quy định tại Điều 30 Luật công đoàn, tranh chấp thuộc phạm vi quyền, trách nhiệm của Công đoàn trong quan hệ lao động thì thẩm quyền, trình tự, thủ tục giải quyết theo pháp luật về giải quyết tranh chấp lao động; Tranh chấp thuộc phạm vi quyền, trách nhiệm của Công đoàn trong các quan hệ khác thì thẩm quyền, trình tự, thủ tục giải quyết theo pháp luật tương ứng có liên quan; Tranh chấp liên quan đến việc không thực hiện hoặc từ chối thực hiện trách nhiệm của đơn vị sử dụng lao động đối với Công đoàn thì công đoàn cơ sở hoặc công đoàn cấp trên trực tiếp cơ sở kiến nghị cơ quan nhà nước có thẩm quyền giải quyết hoặc khởi kiện tại Toà án theo quy định của pháp luật.

Theo quy định tại Điều 31 Luật công đoàn, cơ quan, tổ chức, doanh nghiệp, cá nhân có hành vi vi phạm pháp luật công đoàn thì tùy theo tính chất, mức độ vi phạm mà bị xử lí kỉ luật, xử phạt vi phạm hành chính, bồi thường 
thiệt hại hoặc truy cứu trách nhiệm hình sự theo quy định của pháp luật.

Từ khi thành lập đến nay, Công đoàn Việt Nam luôn nỗ lực trong việc thực hiện chức năng đại diện, bảo vệ người lao động và các chức năng khác của mình. Lợi thế của Công đoàn hiện nay là không phải "cạnh tranh" với bất kì một tổ chức nào khác để có cơ hội thể hiện vai trò của mình đối với người lao động và đối với tiến trình phát triển kinh tế, ồn định chính trị và tiến bộ xã hội ở Việt Nam. Song, điều này cũng chính là thách thức đối với Công đoàn. Liệu có thể "vượt qua chính mình" để "tự khẳng định mình" là tổ chức duy nhất không thể thay thế hay không? là câu hỏi lớn đối với Công đoàn Việt Nam trong giai đoạn hiện nay. Khi mà Công đoàn các cấp, nhất là công đoàn cấp cơ sở đang rất lúng túng trong việc thực hiện vai trò đại diện của mình đối với người lao động ở khu vực kinh tế tư nhân và có vốn đầu tư nước ngoài, khi mà các thế lực đối nghịch đang không ngừng đấu tranh và dùng mọi thủ đoạn để thành lập các tổ chức đại diện khác cho người lao động... thì thách thức đối với Công đoàn Việt Nam càng lớn. Hơn nữa, không ít quy định của Nhà nước về công đoàn đã trở nên lạc hậu trước yêu cầu của thị trường lao động hiện nay, bản thân tổ chức công đoàn cũng còn nhiều vấn đề bất cập trong tổ chức và hoạt động của mình, như:

- Chỉ có một tổ chức công đoàn duy nhất được công nhận là đại diện lao động, trong khi hiệu quả hoạt động chưa thực sự hiệu quả, đặc biệt là ở cấp cở sở. Phần lón các tổ chức công đoàn co sở đã không thực hiện tốt chức năng là một tổ chức đại diện cho người lao động, bảo vệ quyền và lợi ich của ngườ lao động... Lãnh đạo công đoàn phu thuộc vào người sủ dụng lao động. Có nhiều nguoòi lao động không biết rằng một phần tiền lương của ho được trich cho công đoàn cấp trên hoạc cũng có nhũng người lao động không muốn tham gia công đoàn [6].

- Hệ thống công đoàn hiện tại được thiết kế nặng về mô hình tổ chức hành chính, chưa thực sự chú trọng phát triển hệ thống công đoàn ngành.
- Hoạt động của Công đoàn còn phụ thuộc nhiều vào Nhà nước và người sử dụng lao động.

- Pháp luật Việt Nam đã loại trừ một số đối tượng người lao động mà đáng lẽ ra họ cũng có quyền thành lập, gia nhập công đoàn, bao gồm: i) Người lao động không phải là người lao động có quốc tịch Việt Nam; ii) Người lao động trong khu vực phi chính thức, người lao động tự do, không có quan hệ việc làm; iii) Người lao động làm việc cho cá nhân, hộ gia đình.

- Chưa có cơ chế thực sự hợp lí để bảo vệ cán bộ công đoàn cơ sở.

- v.v...

\section{Một số kiến nghị hoàn thiện pháp luật về đại diện lao động khi Việt Nam gia nhập Hiệp định Đối tác Toàn diện và Tiến bộ xuyên Thái Bình Dương}

Nhằm tận dụng cơ hội do CPTPP mang lại, với thực trạng các quy định pháp luật về đại diện lao động ở nước ta như đã phân tích ở trên thì việc đưa ra các giải pháp hoàn thiện là rất cần thiết.

Thứ nhất, cần rà soát toàn bộ hệ thống pháp luật Việt Nam, bắt đầu từ Hiến pháp năm 2013, tiếp đến là các bộ luật, luật liên quan (Bộ luật lao động năm 2012, Luật Công đoàn năm 2012, Luật việc làm năm 2013, Luật an toàn, vệ sinh lao động năm 2015, Luật bảo hiểm xã hội năm 2014, Luật bảo hiểm y tể năm 2008 (sửa đổi, bổ sung năm 2014), Luật người lao động Việt Nam đi làm việc ở nước ngoài theo hợp đồng năm 2006...) và các nghị định, thông tư, quyết định... quy định chi tiết, hướng dẫn thi hành các bộ luật, luật có liên quan đến quyền tự do công đoàn của người lao động. Trên cơ sở đó cần sửa đổi, bổ sung một cách toàn diện, đồng bộ toàn bộ hệ thống pháp luật liên quan, bao gồm cả các quy định về quyền thành lập, gia nhập tổ chức công đoàn, đăng ký công đoàn; thẩm quyền của công đoàn các cấp liên quan đến việc đề xuất xây dựng pháp luật liên quan đến quyền lợi, nghĩa vụ của người lao động; tham gia ý kiến với cơ quan nhà nước có thẩm quyền khi quyết định các vấn đề liên quan đến 
quyền lợi, nghĩa vụ của người lao động; tham gia kiểm tra, giám sát việc thực hiện pháp luật lao động, pháp luật công đoàn; giải quyết hoặc tham gia giải quyết khiếu nại, tố cáo của người lao động; tham gia đối thoại tại nơi làm việc, thương lượng tập thể, ký kết thỏa ước lao động tập thể, xây dựng quy chế dân chủ ở cơ sở tại nơi làm việc; tham gia ý kiến với người sử dụng lao động khi xây dựng nội quy lao động, quy chế tiền lương, quy chế đánh giá người lao động, thang lương, bảng lương; đại diện tập thể lao động trong quá trình giải quyết tranh chấp lao động tập thể; tổ chức, lãnh đạo tập thể lao động tiến hành đình công... Cùng với việc sửa đổi, bổ sung các văn bản pháp luật hiện hành, cần có kế hoạch ban hành các văn bản pháp luật mới như Luật về hội (trong đó điều chỉnh cả việc thành lập, hoạt động của tổ chức công đoàn độc lập của người lao động theo tinh thần của CPTPP) và các văn bản pháp luật cần thiết khác về quyền tự do công đoàn của người lao động.

Thư hai, cần mở rộng đối tượng gia nhập và hoạt động công đoàn cho người nước ngoài làm việc tại Việt Nam. Việc quy định mở rộng đối tượng này phù hợp với tinh thần của các cam kết lao động quốc tế trong đó có Công ước quốc tế về các quyền dân sự và chính trị (năm 1966) của Liên hợp quốc mà Việt Nam đã tham gia.

Thư $b a$, cần quy định cụ thể những đối tượng không được thành lập, gia nhập tổ chức công đoàn trong các doanh nghiệp, đơn vị thuộc khu vực ngoài nhà nước bao gồm: những người quản lí trong các doanh nghiệp (Chủ tịch doanh nghiệp, Chủ tịch Hội đồng quản trị, Tổng Giám đốc, Giám đốc, Hiệu trưởng, Viện trưởng, Phó Chủ tịch Hội đồng quản trị, Phó Tổng giám đốc, Phó Giám đốc, Phó Hiệu trưởng, Phó Viện trưởng được ủy quyền quản lí doanh nghiệp). Những người thân của các đối tượng này không được tham gia tổ chức công đoàn với vai trò là những người lãnh đạo công đoàn.

Quy định này đảm bảo cho Công đoàn được độc lập trong tổ chức và hoạt động công đoàn, hoạt động thực chất và hiệu quả.

Thư $t u$, cần bổ sung quy định cấm người sử dụng lao động tham gia hay can thiệp vào việc phát triển đoàn viên công đoàn, như: cấm kiểm soát danh sách những người gia nhập công đoàn; cấm can thiệp vào việc bầu ban chấp hành công đoàn cơ sở tại doanh nghiệp...

Thư năm, quy định công đoàn cấp trên là tổ chức đại diện cho người lao động ở những nơi chưa thành lập công đoàn cơ sở như hiện này không phù hợp với nguyên tắc tự do công đoàn, khó phát huy hiệu quả trên thực tế, tạo tâm lí cho người lao động về việc không nhất thiết phải có tổ chức công đoàn trong doanh nghiệp. Vì vậy, cần loại bỏ quy định này trong Luật Công đoàn và Bộ luật lao động.

Thư sáu, cần tiếp tục nghiên cứu để có quy định hợp lí hơn về chế độ, chính sách đối với cán bộ công đoàn cơ sở không chuyên trách, thu hút và động viên người lao động có năng lực, nhiệt huyết làm cán bộ công đoàn, trong đó đặc biệt là cơ chế bảo vệ cán bộ công đoàn cơ sở không chuyên trách để những người lao động này yên tâm hoạt động công đoàn.

Thú bảy, cần rà soát, sửa đổi quy định về các biện pháp chế tài đối với hành vi vi phạm pháp luật công đoàn. Các chế tài liên quan đến vi phạm pháp luật về quyền thành lập, gia nhập và hoạt động công đoàn cần được quy định cụ thể và rõ ràng hơn nữa. Mức chế tài phải đảm bảo tính răn đe là cơ sở đề ngăn ngừa các hành vi vi phạm pháp luật xảy ra.

Thứ tám, cần rà soát, hoàn thiện các quy định công đoàn đại diện người lao động thương lượng, ký kết thỏa ước lao động tập thể; xây dựng thang lương, bảng lương, tiền thưởng, an toàn lao động, vệ sinh lao động; xây dựng nội quy, xử lí vi phạm kỉ luật lao động cũng như trong việc giải quyết tranh chấp lao động và đình công... Bởi lẽ, các quy định này nhìn chung chưa thực sự đảm bảo quyền tự do công đoàn, chưa phù hợp với tinh thần của các cam kết quốc tế về quyền tự do lập hội của người lao động.

Thú chín, cần nghiên cứu, nội luật hóa các quy định về tổ chức và hoạt động của đại diện lao động của Công ước số 87 (năm 1948) của ILO về quyền tự do hiệp hội và về việc bảo vệ quyền được liên kết, Công ước số 98 (năm 1949) của ILO về áp dụng những nguyên tắc 
của quyền tổ chức và thương lượng tập thể, CPTPP theo các nguyên tắc: i) Người lao động được tự do gia nhập các tổ chức công đoàn theo lựa chọn của mình (không nhất thiết phải gia nhập hệ thống công đoàn của Tổng Liên đoàn Lao động Việt Nam như hiện nay); ii) Các tổ chức công đoàn phải được độc lập về mặt điều lệ, hoạt động, kinh phí và tư cách; iii) Người lao động được tự chủ trong việc nhận đại diện của công đoàn trong các đơn vị không có công đoàn; iv) Đảm bảo tính đại diện trong việc lựa chọn cán bộ công đoàn; v) Ngăn chặn việc can thiệp của giới chủ vào hoạt động của công đoàn.

Việc hoàn thiện pháp luật về tổ chức đại diện lao động cần có bước đi, lộ trình thích hợp với điều kiện kinh tế - xã hội, đặc điểm hệ thống quan hệ lao động, nền tảng văn hóa của Việt Nam và thời gian được phép chuẩn bị của Việt Nam được quy định trong CPTPP. Bước đi, lộ trình thích hợp sẽ tạo điều kiện cần thiết để có thể chuyển biến tư duy, nhận thức và sự sẵn sàng đón nhận một cuộc cải cách căn bản về vấn đề này của các giới có liên quan trong xã hội; không tạo "cú sốc" cho xã hội và cũng là khoảng thời gian cần thiết để việc chuẩn bị được thực hiện thật chu đáo, đảm bảo tính khả thi của pháp luật sau khi được thông qua hoặc ban hành.

\section{Tài liệu tham khảo}

[1] Nguyễn Quang Quýnh, Luật lao động và An ninh xã hội, Sài Gòn, 1972.

[2] Nguyễn Quang Quýnh, Giáo trình Luật - Lao động, chương trình cử nhân niên khoá 1974 1975, Sài Gòn, 1974.

[3] Văn phòng lao động quốc tế, Tự do hiệp hội, Bộ tổng tập về các nguyên tắc và quyết định của Ủy ban ILO về tự do hiệp hội, Nxb. Lao động Xã hội, 6/2017.

[4] Nghiên cứu về Việt Nam và cơ chế ba bên - Hà Nội, 1995 (Báo cáo của Dự án khu vực Châu Á - Thái Bình Dương về cơ chế ba bên do Na Uy tài trợ).

[5] Trường Đại học Luật Hà Nội, Giáo trình Luật Lao động Việt Nam, Nxb. Công an Nhân dân, Hà Nội, 2009, Tr.147-148.

[6] Bộ Lao động Thương binh và Xã hội, Báo cáo đánh giá 3 năm thực hiện Bộ luật Lao động, tháng 9/2016.

\title{
Improving Vietnamese Law on Representative Worker Organisation as Vietnam Joins the Comprehensive and Progressive Agreement for Trans-Pacific Partnership
}

\author{
Le Thi Hoai Thu \\ VNU School of Law, 144 Xuan Thuy, Cau Giay, Hanoi, Vietnam
}

\begin{abstract}
Representative worker organisation is an organisation that protects workers' legitimate rights and interests. Workers' rights to form and to join representative worker organizations at grassroots level should be respected and protected. This was affirmed by the parties to the Comprehensive and Progressive Agreement for Trans-Pacific Partnership through the labour commitments stipulated in Chapter 19 of СРТPP. This article points out the current legal provisions concerning representative worker organisation in Vietnam. The article concludes with recommendations to improve Vienamese law on representative worker organisation as Vietnam joins CPTPP.
\end{abstract}

Keywords: Representative worker organisation, Trade Union, СРTPP. 